\title{
T-box 2 expression is a useful indicator of the response to neoadjuvant chemotherapy for patients with locally advanced uterine cervical squamous cell carcinoma
}

\author{
YUTA INOUE, TAKESHI FUKUDA, SHIGENORI NANNO, YUICHIRO AWAZU, MASAHIRO SHIMOMURA, \\ HIROAKI MATSUBARA, MAKOTO YAMAUCHI, TOMOYO YASUI and TOSHIYUKI SUMI
}

Department of Obstetrics and Gynecology, Osaka City University Graduate School of Medicine, Osaka 545-8585, Japan

Received March 22, 2021; Accepted August 6, 2021

DOI: $10.3892 / 01.2021 .13016$

\begin{abstract}
Platinum-based concurrent chemoradiotherapy is the standard treatment for patients with locally advanced uterine cervical squamous cell carcinoma. Reducing the tumor size by administering neoadjuvant chemotherapy (NAC) is beneficial for successful hysterectomy, resulting in a more favorable prognosis. Therefore, identifying biomarkers that predict the effectiveness of NAC in patients with cervical squamous cell carcinoma remains a priority. Cancer cells widely express T-box 2 (TBX2), which contributes to the resistance to DNA-damaging chemotherapeutic agents. The present study aimed to determine the association between TBX2 protein expression in tumor tissues and the efficacy of NAC in locally advanced uterine cervical squamous cell carcinoma using immunohistochemistry. Data from 46 patients with locally advanced uterine cervical squamous cell carcinoma were classified into two groups based on their effective or ineffective response to NAC treatment. In addition, the effect of small interfering RNA-mediated knockdown of TBX2 on the sensitivity of cervical cancer cells to cisplatin was investigated in vitro. The results revealed that there were no significant differences in patient clinicopathological features between the NAC effective and NAC ineffective groups. The overall survival of the NAC effective group was significantly improved compared with the NAC ineffective group $(\mathrm{P}=0.007)$. Tumors from the NAC effective group also had significantly downregulated TBX2 expression levels compared with those from the NAC ineffective group $(\mathrm{P}=0.0138)$. Of note, decreased TBX2 expression was indicated to be significantly associated with higher sensitivity to NAC $(\mathrm{P}=0.009)$. The low TBX2 expression group had a more favorable overall survival
\end{abstract}

Correspondence to: Dr Takeshi Fukuda, Department of Obstetrics and Gynecology, Osaka City University Graduate School of Medicine, 1-4-3 Asahimachi, Abeno-ku, Osaka 545-8585, Japan E-mail: takeshif@med.osaka-cu.ac.jp

Key words: uterine cervical squamous cell carcinoma, T-box 2, neoadjuvant chemotherapy, chemoresistance, predictive biomarker compared with the high TBX2 expression group ( $\mathrm{P}=0.049)$. Furthermore, knockdown of TBX2 expression significantly increased cancer cell sensitivity to cisplatin in vitro. In conclusion, the results of the present study suggested that TBX2 expression may be a useful predictor of the response to NAC in patients with locally advanced uterine cervical squamous cell carcinoma.

\section{Introduction}

Cervical cancer, one of the most common types of malignancy worldwide, is the fourth leading cause of cancer-associated mortality among females (1). Despite significant advances in prevention, screening and diagnostic methods, certain cases are diagnosed at locally advanced stages, such as Federation of Gynecology and Obstetrics (FIGO) stages IIIA, IIIB and IVA. Platinum-based concurrent chemoradiotherapy (CCRT) is currently used as the standard treatment strategy for patients with advanced disease (2-4). However, compared with patients with early-stage disease, the prognosis of these patients is unfavorable, with a 5-year survival rate of $<60 \%(5,6)$. Reducing the tumor size by administering neoadjuvant chemotherapy (NAC) was indicated to facilitate the success of hysterectomy, resulting in improved prognosis $(7,8)$; therefore, the use of NAC for the treatment of cervical cancer has attracted significant attention in recent years (8). However, if NAC fails to sufficiently reduce the tumor size to perform hysterectomy, the treatment strategy is altered to radiation therapy, which delays the initiation of core treatment and results in unfavorable prognosis $(9,10)$. Thus, if it were possible to predict the response to NAC, this would have the potential to become one of the major strategies to treat patients with locally advanced cervical squamous cell carcinoma, providing a greater variety of treatment options for patients. Therefore, to identify eligible patients to receive NAC, there is an urgent requirement to discover biomarkers indicating the response to NAC in patients with locally advanced cervical squamous cell carcinoma.

The T-box (TBX) gene family consists of five subfamilies, including T, Tbx1, Tbx2, Tbx6 and Tbr1. TBX genes have a crucial role in organogenesis and pattern formation in vertebrate and invertebrate species (11). Transcription factors of the T-box 
families serve essential roles throughout development (12). Increased expression levels of TBX2 and TBX3, which are included in the Tbx2 subfamily, are thought to be associated with the oncogenic process. TBX2 is a transcription factor involved in embryonic development, cell cycle regulation and cancer $(13,14)$. Cancer cells widely express TBX2 and it has been indicated to allow cancer cells to bypass senescence by suppressing the cell cycle regulators p21 and p14 (15-17). Suppressing p21 reportedly resulted in chemoresistance by modulating the $\mathrm{G}_{1} / \mathrm{S}$ cell cycle transition and inhibiting chemotherapy-induced apoptosis in lung cancer(18). In addition, TBX2 expression levels were indicated to be upregulated in melanoma (16), breast cancer $(17,19)$, prostate cancer $(20)$, non-small cell lung cancer (21), gastric cancer (22), laryngeal squamous cell carcinoma (23) and pancreatic cancer (24). Furthermore, ectopic TBX2 expression was associated with resistance to DNA-damaging chemotherapeutic agents, such as doxorubicin and cisplatin (25-27). However, to the best of our knowledge, the relationship between TBX2 expression and platinum-based chemotherapy in cervical squamous cell carcinoma has remained largely elusive.

The present study investigated the value of TBX2 expression as an indicator of the effectiveness of NAC by determining the relationship between TBX2 expression in tumors and the response to NAC in patients with locally advanced uterine cervical squamous carcinoma. Furthermore, the effect of small interfering RNA (siRNA/si)-mediated knockdown of TBX2 expression on the sensitivity of cervical cancer cells to cisplatin was evaluated in vitro.

\section{Materials and methods}

Patient study. A total of 46 patients with FIGO stage IIIA and IIIB uterine cervical squamous cell carcinoma who underwent NAC at Osaka City University Hospital (Osaka, Japan) between April 1995 and March 2010, were retrospectively evaluated. The inclusion criteria were as follows: Patients were diagnosed as uterine cervical squamous cell carcinoma histologically, stages IIIA and IIIB, patients who underwent NAC and patients with available medical records to analyze. Patients for whom sufficient medical records were unavailable were excluded. A punch biopsy of tumor tissue was performed before the administration of chemotherapy (cisplatin). Clinical variables including age, FIGO stage, tumor size and the effect of NAC treatment were obtained for each patient. Patients were divided into two groups based on their response to NAC: i) NAC effective group $(n=25)$, which included patients who were successfully treated with NAC, underwent a hysterectomy and received radiotherapy; and ii) NAC ineffective group $(n=21)$, which comprised patients who experienced NAC treatment failure and only received radiotherapy. The effect of NAC was evaluated by pelvic examination and computed tomography or magnetic resonance imaging. Successful NAC was defined as the stage being reduced to stage I or II, making a hysterectomy possible, while in cases with unsuccessful NAC, the tumor size was not sufficiently reduced to perform a hysterectomy. All patients were administered 50,75 or $100 \mathrm{mg} / \mathrm{m}^{2}$ cisplatin (Bristol Myers Squibb), which was based on the renal function and age of the patients (28), intra-arterially via balloon-occluded arterial infusion three times over $30 \mathrm{~min}$.
Written informed consent was obtained from all patients prior to the tumor biopsy and the experimental protocol was approved by the Institutional Review Board of Osaka City University Hospital (Osaka, Japan; approval no. 4276).

Immunohistochemical (IHC) staining. The sections $(4 \mu \mathrm{m}$ thick) were prepared from the paraffin-embedded tissue blocks. The sections were deparaffinized and endogenous peroxidase activity was blocked by immersing in $3 \%$ hydrogen peroxidase in methanol. Antigen retrieval was performed by immersing the samples in $10 \mathrm{~mm}$ citrate buffer (pH 6.0) and heating the samples in an autoclave at $110^{\circ} \mathrm{C}$ for $20 \mathrm{~min}$. IHC staining was performed using the Dako LSAB2 Peroxidase kit (cat. no. K0675; Agilent Technologies, Inc.). In brief, after blocking endogenous peroxidase activity and performing antigen retrieval, tissue sections were incubated with a rabbit polyclonal anti-TBX2 antibody (1:50 dilution; cat. no. LS-C402301; LifeSpan BioSciences, Inc.) in a humidity chamber at $4^{\circ} \mathrm{C}$ overnight. Following incubation with the primary antibody, the sections were incubated with biotinylated goat anti-mouse and anti-rabbit immunoglobulin G secondary antibodies included in the Dako LSAB2 Peroxidase kit (cat. no. K0675; Agilent Technologies, Inc.) at room temperature for $10 \mathrm{~min}$. The sections were subsequently incubated with a streptavidin-peroxidase complex and 3,3'-diaminobenzidine was used as the chromogen. The specificity control was prepared in the same way with omission of the primary antibodies.

TBX2 expression levels were quantitatively scored according to the weighted scoring method established by Sinicrope et al (29). The IHC score was determined using a light microscope (magnification, x400) based on the average percentage of stained tumor cells, which was scored using a scale of $0-4$ as follows: $0(<5 \%), 1(5-25 \%), 2(25-50 \%), 3$ $(50-75 \%)$ and $4(>75 \%)$. The intensity of cell staining was scored as $1+$ (weak), 2+ (moderate) and 3+ (intense). Weighted scores were calculated by multiplying the score of the stained tumor cell percentage and the score of the staining intensity.

Cell lines and culture. The CaSki cervical cancer cell line (cat. no. IFO50007) was purchased from the Japanese Collection of Research Bioresources Cell Bank. Cells were cultured in RPMI-1640 medium (Gibco; Thermo Fisher Scientific, Inc.) supplemented with 10\% FBS (Gibco; Thermo Fisher Scientific, Inc.) and $1 \%$ penicillin, and maintained in an incubator with $5 \% \mathrm{CO}_{2}$ at $37^{\circ} \mathrm{C}$.

Small interfering (si)RNA transfection and cell survival assay. CaSki cells were seeded into 96-well plates $\left(2 \times 10^{3}\right.$ cells/well) and divided into two groups: i) Treated group, in which cells were transfected with TBX2-specific siRNA (customized siTBX2; Sigma-Aldrich; Merck KGaA); and ii) control group, in which cells were transfected with nontargeting siRNA (Mission ${ }^{\circledR}$ Universal Negative Control \#1; cat. no. SIC001-10NMOL; Sigma-Aldrich; Merck KGaA). The siTBX2 sequence was as follows: Sense, 5'-CCAAUG AACUGCAGAGCAU[dT][dT]-3' and antisense, 5'-AUGCUC UGCAGUUCAUUGG[dT][dT]-3'. siTBX2 transfections were performed using Lipofectamine ${ }^{\circledR}$ RNAiMax (Invitrogen; Thermo Fisher Scientific, Inc.) strictly following the manufacturer's protocol. After confirming cell adhesion in both 
Table I. Clinicopathological features of patients in the NAC effective and NAC ineffective groups.

\begin{tabular}{lcc}
\hline Variable & NAC effective group $(\mathrm{n}=25)$ & NAC ineffective group $(\mathrm{n}=21)$ \\
\hline Age, years & & $53.7 \pm 11.2$ \\
Mean \pm SD & $49.3 \pm 13.2$ & $37-68$ \\
Range & $24-69$ & $152.1 \pm 5.09$ \\
Body height, cm & $154.5 \pm 6.67$ & $143-162$ \\
Mean \pm SD & $138-166$ & $48.73 \pm 8.19$ \\
Range & & $38-67$ \\
Body weight, kg & $53.01 \pm 8.76$ & $0.182^{\mathrm{a}}$ \\
Mean \pm SD & $37-78$ & $0.096^{\mathrm{a}}$ \\
Range & & $1^{\mathrm{b}}$ \\
International Federation of Gynecology & 1 & 21 \\
and Obstetrics stage & 24 & $50.2 \pm 12.5$ \\
IIIA & & $0.464^{\mathrm{a}}$ \\
IIIB & $46.6 \pm 16.8$ & 0 \\
Tumor size, mm & & \\
Mean \pm SD & & \\
\hline
\end{tabular}

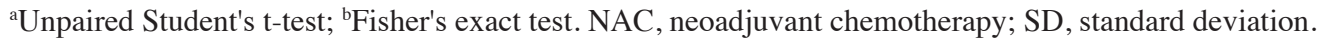

groups, the control group was provided with fresh medium containing nontargeting siRNA transfection complexes, whereas the transfection group was treated with fresh medium containing siTBX2 transfection complexes. Following $24 \mathrm{~h}$ of incubation at $37^{\circ} \mathrm{C}$, the cells in each group were incubated for an additional $48 \mathrm{~h}$ at $37^{\circ} \mathrm{C}$ in fresh medium containing 0 , $2.5,5.0,7.5,10$ or $50 \mu \mathrm{M}$ cisplatin. Cell viability was subsequently measured using a Cell Counting Kit (CCK)-8 assay (Dojindo Molecular Technologies, Inc.). In brief, $10 \mu \mathrm{l} \mathrm{CCK-8}$ and $100 \mu \mathrm{l}$ RPMI-1640 were added to each well, followed by incubation at $37^{\circ} \mathrm{C}$ for $2 \mathrm{~h}$. The absorbance of each well was measured at a wavelength of $450 \mathrm{~nm}$ using a microplate reader (Corona Electric Co., Ltd.). The percentage of viable cells in comparison with the control cells was evaluated using dose-response curves.

Reverse transcription-quantitative $P C R$ (RT-qPCR). RT-qPCR was performed using TaqMan chemistry. The procedure was performed according to the manufacturer's protocol. TaqMan primer and probes for TBX2 (cat. no. Hs00911929_m1) and hypoxanthine phosphoribosyltransferase 1 (cat. no. Hs02800695_m1) were obtained from Thermo Fisher Scientific, Inc. Total RNA was extracted from CaSki cells using the RNeasy Mini kit (Qiagen $\mathrm{GmbH}$ ). Total RNA (1 $\mu \mathrm{g})$ was reverse transcribed into cDNA using a High-Capacity cDNA Reverse Transcription kit (Thermo Fisher Scientific, Inc.). qPCR was subsequently performed on an ABI 7500 Fast Real-Time PCR detection system (Applied Biosystems; Thermo Fisher Scientific, Inc.) using TaqMan Fast Universal PCR Master Mix (Thermo Fisher Scientific, Inc.). The following thermocycling conditions were used for qPCR: Initial denaturation at $95^{\circ} \mathrm{C}$ for $20 \mathrm{sec}$, followed by 40 cycles of $95^{\circ} \mathrm{C}$ for $3 \mathrm{sec}$ and $60^{\circ} \mathrm{C}$ for $30 \mathrm{sec}$. The $2^{-\Delta \Delta \mathrm{Cq}}$ method was used to calculate the relative changes in gene expression for the RT-qPCR experiments (30).
Statistical analysis. Statistical analysis was performed using EZR version 1.3 software (Saitama Medical Center, Jichi Medical University) (31). Values are expressed as the mean \pm standard deviation. Statistically significant differences between groups were determined using unpaired Student's t-tests. Fisher's exact test was used to determine the association between categorical variables in the different patient groups. The Kaplan-Meier method and log-rank tests were used for survival analysis. Mann-Whitney U-tests were used to compare the IHC weighted scores. A receiver operating characteristic (ROC) curve was used to determine the cutoff value of TBX2 score to predict the effect of NAC treatment. $\mathrm{P}<0.05$ was considered to indicate a statistically significant difference.

\section{Results}

Patient characteristics. The 46 patients in the present study were divided into two groups based on treatment efficacy: NAC effective group $(n=25)$ and NAC ineffective group $(n=21)$. Differences in age, body height, body weight, FIGO stage and tumor size were analyzed and no statistically significant differences in these variables were identified between the two groups (Table I).

TBX2 protein expression levels in cervical squamous cell carcinoma tissues. IHC was used to analyze TBX2 protein expression levels in cervical squamous cell carcinoma tissues and the weighted scores of both groups were calculated (Fig. 1A-E). TBX2 was indicated to be predominantly located in the cell nuclei. The weighted score of the NAC ineffective group was significantly increased compared with that in the NAC effective group ( $\mathrm{P}=0.0138$; Fig. 1E). A ROC curve was used to determine the cutoff value of TBX2 scores to predict the effectiveness of NAC treatment (Fig. 1F). The ROC curve indicated that with a cutoff value of 6 , TBX2 scores were 

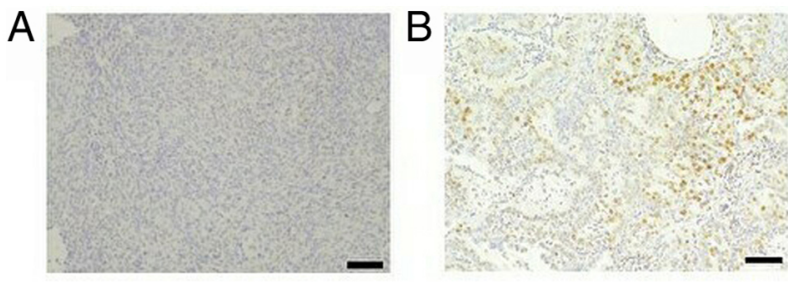

E

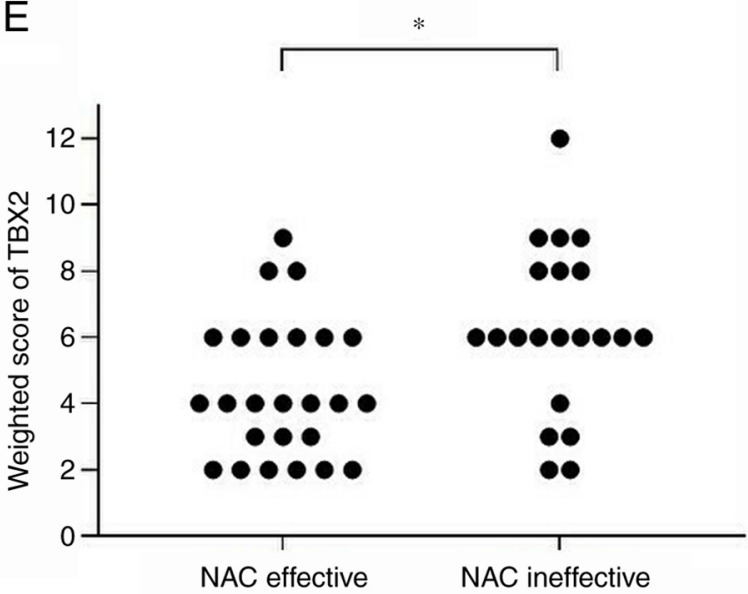

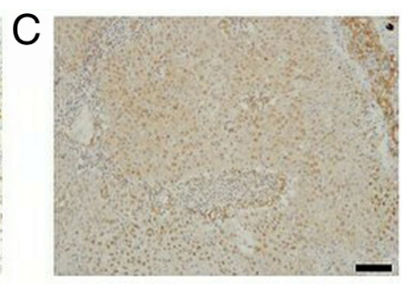
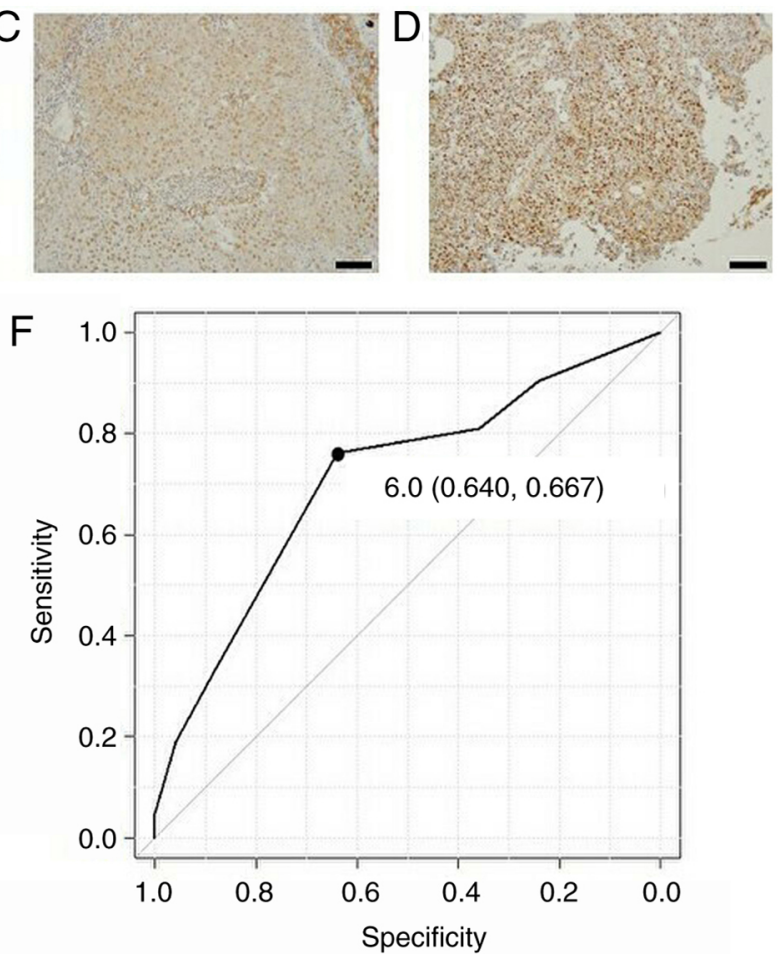

Figure 1. IHC staining for TBX2 expression in punch biopsy samples obtained prior to the initiation of treatment. (A) Negative control IHC staining was performed without the primary antibody. Representative sections with a weighted score of (B) 4, (C) 6 and (D) 12 following staining with an anti-TBX2 primary antibody. Hematoxylin was used for counterstaining (scale bars, $50 \mu \mathrm{m}$ ). (E) Weighted scores for TBX2 protein expression levels in punch biopsy samples obtained prior to the initiation of treatment. TBX2 expression levels were significantly downregulated in the NAC effective group compared with the NAC ineffective group. ${ }^{*} \mathrm{P}=0.0138$ (Mann-Whitney U-test). (F) Receiver operating characteristic curve for determining the TBX2 cutoff score to evaluate the effectiveness of NAC. With a cutoff value of 6 , the specificity was $64.0 \%(0.640)$ and the sensitivity was $66.7 \%(0.667)$. The area under the curve was 0.662 with a $95 \%$ confidence interval of 0.505-0.819. TBX2, T-box 2; NAC, neoadjuvant chemotherapy; IHC, immunohistochemistry.

able to predict the effectiveness of NAC, with a specificity of $64 \%$ and sensitivity of $67 \%$. The area under the curve was 0.662 with a $95 \%$ confidence interval of $0.505-0.819$. The patients were subsequently divided into the following two groups based on their weighted scores: Low TBX2 expression (weighted score, $\leq 4 ; \mathrm{n}=21$ ) and high $\mathrm{TBX} 2$ expression (weighted score, $\geq 6 ; n=25$ ). No statistically significant differences were observed in the patient characteristics between these two groups (Table II). These results suggested that TBX2 expression may be associated with the efficacy of NAC.

Association between NAC sensitivity and TBX2 expression. Whether there was a difference in NAC effectiveness between the low TBX2 expression and high TBX2 expression groups was subsequently evaluated. In the low TBX2 expression group, NAC was effective in $76.2 \%$ of cases. By contrast, in the high TBX2 expression group, NAC was effective in $36 \%$ of patients. Of note, this difference in effectiveness of NAC between the two groups was statistically significant $(\mathrm{P}=0.009$; Table III). These results indicated that the low TBX2 expression group may be more sensitive to NAC compared with the high TBX2 expression group.

Survival analysis. The patients' follow-up period varied from 124 to 5,015 days. The overall survival of patients in the NAC effective group was significantly improved compared with that in the NAC ineffective group ( $\mathrm{P}=0.007$; Fig. $2 \mathrm{~A})$. In addition, the low TBX2 expression group had a more favorable overall survival compared with the high TBX2 expression group ( $\mathrm{P}=0.049$; Fig. $2 \mathrm{~B}$ ). These results suggested that TBX2 expression may help predict the prognosis of patients with locally advanced uterine cervical squamous cell carcinoma who received NAC treatment.

Effect of TBX2 knockdown on the cisplatin sensitivity of cervical cancer cells. RT-qPCR analysis revealed that TBX2 mRNA expression levels were significantly downregulated following transfection with siTBX2 compared with control cells (Fig. 3A). Of note, CaSki cells transfected with siTBX2 had a significantly enhanced sensitivity to cisplatin compared with control cells $(\mathrm{P}<0.01$; Fig. 3B). These results suggested that TBX2 may be involved in the mechanism through which cisplatin exerts cytotoxic effects on cancer cells.

\section{Discussion}

NAC is a useful treatment option for patients with cervical cancer; therefore, a significant amount of research has focused on the use of NAC for patients with cervical cancer in recent years. For instance, Sala et al (8) reported that NAC improved the survival outcome for patients with stage IB2-IVA uterine cervical cancer in a multicenter retrospective analysis. Chen et al (32) demonstrated that NAC reduced the probability of lymph node metastasis for patients with stage IB1-IIB uterine cervical cancer. In addition, de Vincenzo et al (33) reported that the administration of NAC followed by conization in 
Table II. Clinicopathological features of patients in the TBX2 low and high groups.

\begin{tabular}{|c|c|c|c|}
\hline Variable & $\begin{array}{l}\text { Low TBX2 expression } \\
\quad(\text { score } \leq 4)(n=21)\end{array}$ & $\begin{array}{l}\text { High TBX2 expression } \\
\quad(\text { score } \geq 6)(n=25)\end{array}$ & P-value \\
\hline \multicolumn{4}{|l|}{ Age, years } \\
\hline Mean $\pm \mathrm{SD}$ & $50.4 \pm 12.7$ & $52.0 \pm 12.6$ & $0.659^{\mathrm{a}}$ \\
\hline Range & 24-69 & $29-68$ & \\
\hline \multicolumn{4}{|l|}{ Body height, cm } \\
\hline Mean \pm SD & $154.0 \pm 7.22$ & $153.0 \pm 5.00$ & $0.573^{\mathrm{a}}$ \\
\hline Range & 138-166 & $143-162$ & \\
\hline \multicolumn{4}{|l|}{ Body weight, kg } \\
\hline Mean \pm SD & $53.10 \pm 9.61$ & $49.34 \pm 7.60$ & $0.146^{\mathrm{a}}$ \\
\hline Range & $37-78$ & $38-67$ & \\
\hline $\begin{array}{l}\text { International Federation of Gynecology } \\
\text { and Obstetrics stage }\end{array}$ & & & $1^{\mathrm{b}}$ \\
\hline IIIA & 1 & 0 & \\
\hline IIIB & 20 & 25 & \\
\hline Tumor size, mm & & & $0.439^{\mathrm{a}}$ \\
\hline Mean $\pm \mathrm{SD}$ & $46.2 \pm 15.2$ & $50.0 \pm 15.0$ & \\
\hline
\end{tabular}

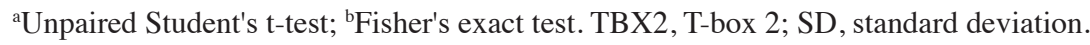

Table III. Number of patients with low (score of $\leq 4$ ) and high (score of $\geq 6$ ) TBX2 expression in the NAC effective and NAC ineffective groups.

\begin{tabular}{lccc}
\hline $\begin{array}{l}\text { TBX2 } \\
\text { expression }\end{array}$ & $\begin{array}{c}\text { NAC effective } \\
\text { group }\end{array}$ & $\begin{array}{c}\text { NAC ineffective } \\
\text { group }\end{array}$ & P-value \\
\hline Low & $16(76.2)$ & $5(23.8)$ & $0.009^{\mathrm{a}}$ \\
High & $9(36.0)$ & $16(64.0)$ & \\
\hline
\end{tabular}

${ }^{\text {a}}$ Fisher's exact test. Values are expressed as n (\%). TBX2, T-box 2; NAC, neoadjuvant chemotherapy.

stage IB2-IIA1 cervical cancer resulted in improved fertility. Sun et al (34) also reported that treatment with NAC provided an improved quality of life for patients with stage IB2-IIA cervical cancer.

Platinum-based CCRT is currently used as a standard treatment strategy for patients with locally advanced uterine cervical squamous cell carcinoma (2-4). However, the prognosis of these patients remains unfavorable, suggesting that improvements in the available treatments are required. Effective NAC treatment has been reported to reduce the tumor size, allow patients to undergo hysterectomy and potentially improve patient prognosis $(7,8)$. However, if NAC is ineffective, there are currently no alternatives to surgical resection other than radiotherapy, which may lead to unfavorable prognosis due to the delay in the initiation of core treatment (35). Therefore, identifying biomarkers that are able to predict the efficacy of NAC remains important for selecting patients that are likely to benefit from NAC treatment.
Cisplatin and other platinum-containing drugs exert antitumor effects by covalently binding to DNA in cancer cells (36), which facilitates apoptosis by inhibiting DNA replication (37). Usually, platinum-based chemotherapy is initially effective; however, cancer cells may later develop resistance to these agents (38). Potential mechanisms of platinum resistance include decreased cellular uptake of cisplatin $(39,40)$, increased cisplatin detoxification capacity (41), enhanced DNA damage repair capacity $(42,43)$, deactivation of apoptotic signaling pathways (44) and other epigenetic modifications that occur at both the cellular and molecular levels $(45,46)$.

TBX2 is a transcription factor that was discovered to be involved in the regulation of cell cycle progression during cancer and embryonic development $(13,14)$. TBX2 was indicated to be widely expressed in cancer cells and permits them to bypass senescence by suppressing the cell cycle regulators $\mathrm{p} 21$ and $\mathrm{p} 14^{\mathrm{ARF}}(15-17)$. In addition to its role in cell cycle regulation, p21 also mediates apoptotic signaling pathways (47). Several studies have demonstrated that p21 has a proapoptotic role in cancer (48). For instance, p21 induction by RNA activation enhanced antitumor activity by promoting cell cycle arrest and apoptotic cell death in bladder cancer cells (48). Transcriptional activation of p21 inhibited the viability of hepatocellular carcinoma cells and significantly increased cell apoptosis by downregulating the expression levels of anti-apoptotic proteins, including survivin and $\mathrm{Bcl}-\mathrm{xL}$, and upregulating the expression of executioner caspase-3 and -9 (49). In addition, TBX2 has been reported to contribute to cancer cell resistance to therapeutic agents, such as cisplatin $(25,26)$, by modulating the $G_{1} / S$ cell cycle transition and inhibiting chemotherapy-induced apoptosis via suppression of the cell cycle regulator p21 (18). Those reports regarding cancer cell resistance to cisplatin are consistent with the present results and they support the present results. 


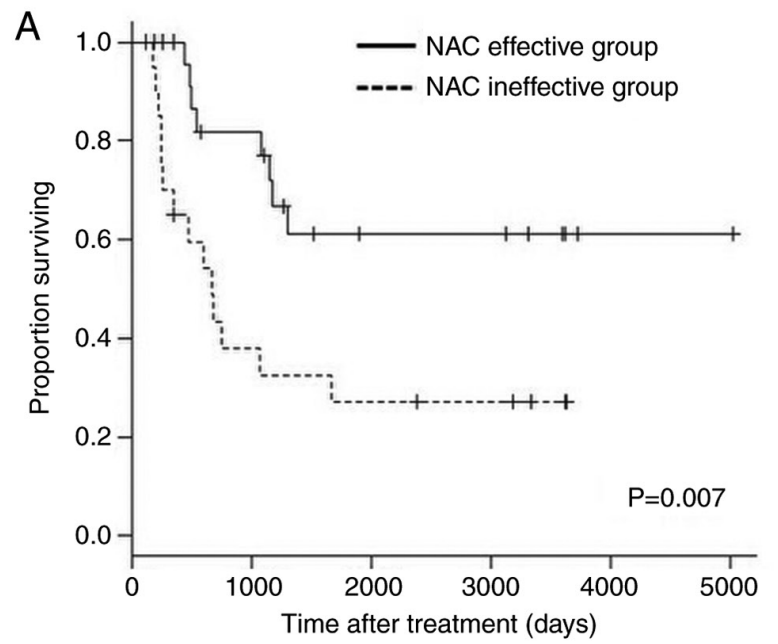

Number at risk

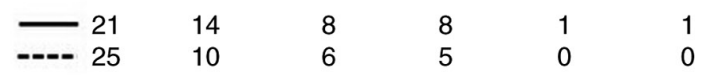

B

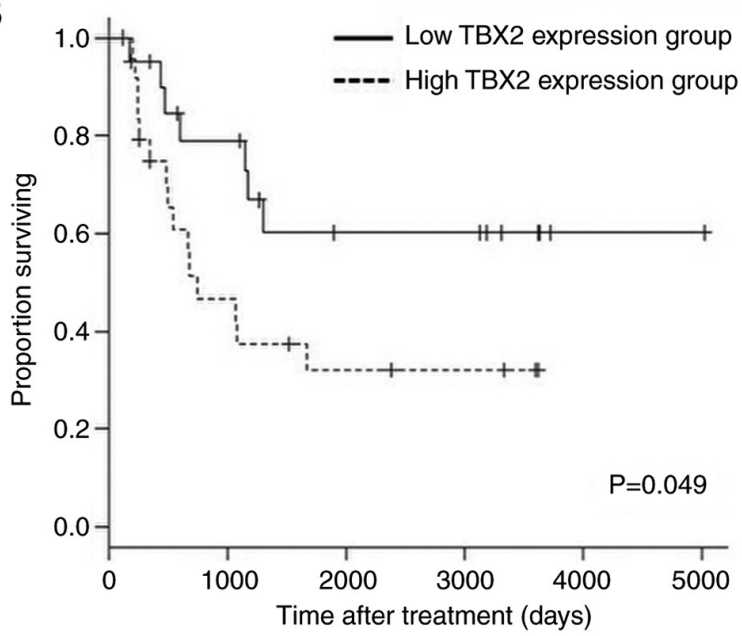

Number at risk

\begin{tabular}{|c|c|c|}
\hline & 14 & 8 \\
\hline ---- 25 & 10 & 6 \\
\hline
\end{tabular}

Figure 2. Kaplan-Meier analysis of overall survival of the patients. (A) Comparison of survival between the NAC effective group ( $\mathrm{n}=25$ ) and NAC ineffective group ( $\mathrm{n}=21)$. Solid line, NAC effective group; dashed line, NAC ineffective group. The NAC effective group had a significantly improved overall survival compared with the NAC ineffective group ( $\mathrm{P}=0.007$; log-rank test). (B) Comparison of survival between the low TBX2 expression group ( $\mathrm{n}=21$ ) and high TBX2 expression group $(\mathrm{n}=25)$. Solid line, low TBX2 expression; dashed line, high TBX2 expression. The low TBX2 expression group had significantly improved overall survival compared with the high TBX2 expression group ( $\mathrm{P}=0.049$; log-rank test). Any censored datapoints represent missing follow-up data. TBX2, T-box 2; NAC, neoadjuvant chemotherapy.
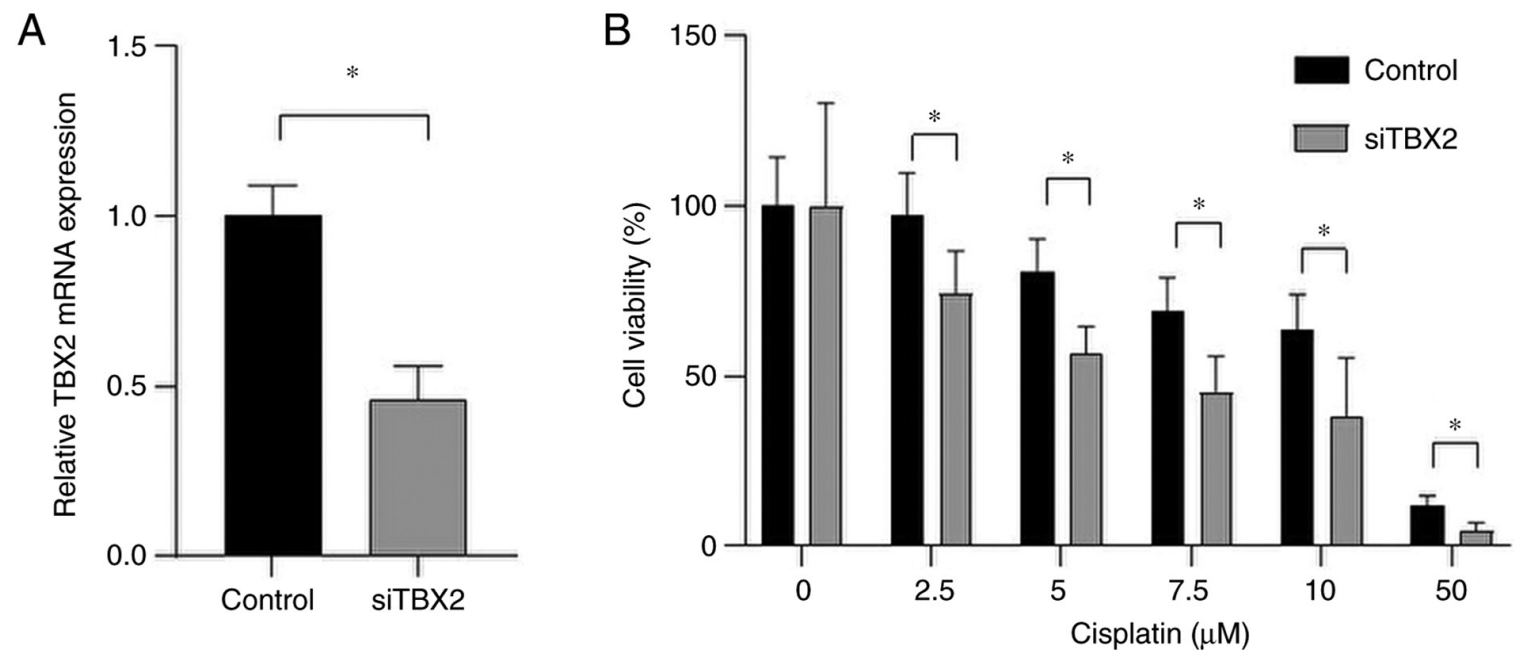

Figure 3. Effect of siTBX2 on TBX2 mRNA expression levels and cell viability in CaSki cervical cancer cells. (A) TBX2 mRNA expression levels were significantly downregulated following knockdown of TBX2 in CaSki cells. The mRNA expression levels were normalized to hypoxanthine phosphoribosyltransferase 1 mRNA. (B) Viability of CaSki cells in the presence or absence of siRNA specific for TBX2 after incubation for $24 \mathrm{~h}$ with $0,2.5,5.0,7.5,10$ or $50 \mu \mathrm{M}$ cisplatin. " $\mathrm{P}<0.01$ vs. Control (unpaired Student's t-test). Values are expressed as the mean \pm standard deviation. TBX2, T-box 2; si/siRNA, small interfering RNA.

The results of the present study predicted NAC efficacy in patients with locally advanced uterine cervical squamous cell carcinoma by determining TBX2 expression levels in histological samples obtained prior to the initiation of treatment. Patients with downregulated TBX2 protein expression levels were more susceptible to NAC treatment and more likely to undergo successful surgery following NAC treatment, resulting in improved prognosis.

To the best of our knowledge, the present study was the first to suggest the potential of determining TBX2 expression in tumors to predict the efficacy of NAC treatment in patients with locally advanced uterine cervical squamous cell carcinoma. In addition, these results may improve the response to NAC treatment in patients with any stage of cervical squamous cell carcinoma by making it possible to select eligible patients that are likely to benefit from NAC treatment.

However, only 46 patients were included in the present retrospective study; therefore, the major limitations of the present study are the small number of patients used and the retrospective design. And even though human papillomavirus (HPV) infection status is a crucial factor when investigating uterine cervical cancer, those data of the 
patients included in the present study were not available. Further studies involving a larger number of cases and data including the HPV infection status are required to address this issue and validate the present findings. Furthermore, the study was performed at a single institution without any external validation. In addition, the present study remains a hypothesis-exploratory study. Therefore, future studies are required to be performed at multiple centers to validate the present results.

In conclusion, the results of the present study indicated that TBX2 expression may represent a useful predictor of the response to NAC for patients with locally advanced uterine cervical squamous cell carcinoma. These results may be applied to patients with any stage of cervical squamous cell carcinoma to predict whether they may benefit from NAC treatment.

\section{Acknowledgements}

The authors would like to thank Dr Yukimi Kira (Research Support Platform of Osaka City University Graduate School of Medicine; Osaka, Japan) for their technical support.

\section{Funding}

The present study was funded by The Osaka Medical Research Foundation for Intractable Diseases (grant no. 26-2-47).

\section{Availability of data and materials}

The datasets used and/or analyzed during the current study are available from the corresponding author upon reasonable request.

\section{Authors' contributions}

YI, TF and TS designed the study. YI, HM, SN, YA, MS and MY performed the experiments and collected the data. YI, TF, TY and TS analyzed the data. YI and TF wrote the manuscript. YI and TF confirm the authenticity of all the raw data. All authors read and approved the final manuscript.

\section{Ethics approval and consent to participate}

The present study protocol was approved by the Institutional Review Board of Osaka City University Hospital (approval no. 4276; Osaka, Japan). Written informed consent was obtained from all patients prior to participation.

\section{Patient consent for publication}

Not applicable.

\section{Competing interests}

The authors declare that they have no competing interests.

\section{References}

1. Jemal A, Bray F, Center MM, Ferlay J, Ward E and Forman D Global cancer statistics. CA Cancer J Clin 61: 69-90, 2011.
2. Pecorelli S: Revised FIGO staging for carcinoma of the vulva, cervix and endometrium. Int J Gynaecol Obstet 105: 103-104, 2009.

3. Japan Society of Gynecologic Oncology (eds). Formulation Committee of the Treatment Guidelines for Cervical Cancer, 2011. Kanehara \& Co., Tokyo, 2011 (In Japanese).

4. National Comprehensive Cancer Network. NCCN Clinical Practice Guidelines in Oncology. Cervical Cancer Version II, 2013. https://www2.tri-kobe.org/nccn/guideline/ gynecological/english/cervical.pdf.

5. Morris M, Eifel PJ, Lu J, Grigsby PW, Levenback C, Stevens RE, Rotman M, Gershenson DM and Mutch DG: Pelvic radiation with concurrent chemotherapy compared with pelvic and para-aortic radiation for high-risk cervical cancer. N Engl J Med 340: 1137-1143, 1999.

6. Eifel PJ, Winter K, Morris M, Levenback C, Grigsby PW, Cooper J, Rotman M, Gershenson D and Mutch DG: Pelvic irradiation with concurrent chemotherapy versus pelvic and para-aortic irradiation for high-risk cervical cancer: An update of radiation therapy oncology group trial (RTOG) 90-01. J Clin Oncol 22: 872-880, 2004.

7. Ishiko O, Sumi T, Yasui T, Matsumoto Y, Kawamura N, Ogita S, Kamino T, Nakamura $\mathrm{K}$ and Yamada R: Balloon-occluded arterial infusion chemotherapy, simple total hysterectomy and radiotherapy as a useful combination-therapy for advanced cancer of the uterine cervix. Oncol Rep 7: 141-144, 2000.

8. Sala P, Bogliolo S, Barra F, Fazio A, Maramai M, Cassani C, Gardella B, Babilonti L, Giannelli F, Mammoliti S, et al: Neoadjuvant chemotherapy followed by radical surgery versus concurrent chemo-radiotherapy in the treatment of locally advanced cervical cancer: A multicenter retrospective analysis. J Invest Surg 8: 1-7, 2020.

9. Souhami L, Gil RA, Allan SE, Canary PC, Araújo CM, Pinto LH and Silveira TR: A randomized trial of chemotherapy followed by pelvic radiation therapy in stage IIIB carcinoma of the cervix. J Clin Oncol 9: 970-977, 1991.

10. Tattersall MH, Lorvidhaya V, Vootiprux V, Cheirsilpa A, Wong F, Azhar T, Lee HP, Kang SB, Manalo A and Yen MS: Randomized trial of epirubicin and cisplatin chemotherapy followed by pelvic radiation in locally advanced cervical cancer. Cervical cancer study group of the Asian oceanian clinical oncology association. J Clin Oncol 13: 444-451, 1995.

11. Chang F, Xing P, Song F, Du X, Wang G, Chen K and Yang J: The role of T-box genes in the tumorigenesis and progression of cancer. Oncol Lett 12: 4305-4311, 2016.

12. Papaioannou VE: The T-box gene family: Emerging roles in development, stem cells and cancer. Development 141: 3819-3833, 2014.

13. Bilican B and Goding CR: Cell cycle regulation of the T-box transcription factor tbx2. Exp Cell Res 312: 2358-2366, 2006.

14. Abrahams A, Parker MI and Prince S: The T-box transcription factor Tbx2: Its role in development and possible implication in cancer. IUBMB Life 62: 92-102, 2010.

15. Peres J, Davis E, Mowla S, Bennett DC, Li JA, Wansleben S and Prince S: The highly homologous T-Box transcription factors, TBX2 and TBX3, have distinct roles in the oncogenic process. Genes Cancer 1: 272-282, 2010.

16. Vance KW, Carreira S, Brosch G and Goding CR: Tbx2 is overexpressed and plays an important role in maintaining proliferation and suppression of senescence in melanomas. Cancer Res 65: 2260-2268, 2005.

17. Jacobs JJ, Keblusek P, Robanus-Maandag E, Kristel P, Lingbeek M, Nederlof PM, van Welsem T, van de Vijver MJ, Koh EY, Daley GQ and van Lohuizen M: Senescence bypass screen identifies TBX2, which represses Cdkn2a (p19(ARF) and is amplified in a subset of human breast cancers. Nat Genet 26: 291-299, 2000.

18. Wang H, Zhu LJ, Yang YC, Wang ZX and Wang R: miR-224 promotes the chemoresistance of human lung adenocarcinoma cells to cisplatin via regulating $\mathrm{G}_{1} / \mathrm{S}$ transition and apoptosis by targeting p21(WAF1/CIP1). Br J Cancer 15: 339-354, 2014.

19. Taneja P, Maglic D, Kai F, Zhu S, Kendig RD, Fry EA and Inoue K: Classical and novel prognostic markers for breast cancer and their clinical significance. Clin Med Insights Oncol 4: 15-34, 2010.

20. Nandana S, Tripathi M, Duan P, Chu CY, Mishra R, Liu C, Jin R, Yamashita H, Zayzafoon M, Bhowmick NA, et al: Bone metastasis of prostate cancer can be therapeutically targeted at the TBX2-WNT signaling axis. Cancer Res 77: 1331-1344, 2017.

21. Zhang Z and Guo Y: High TBX2 expression predicts poor prognosis in non-small cell lung cancer. Neoplasma 61: 476-480, 2014. 
22. Yu H, Liu BO, Liu A, Li K and Zhao H: T-box 2 expression predicts poor prognosis in gastric cancer. Oncol Lett 10: $1689-1693,2015$.

23. Huang Y,Li Z,Zhong Q, Li G, Zhang Y and Huang Z: Association of TBX2 and P21 expression with clinicopathological features and survival of laryngeal squamous cell carcinoma. Int J Clin Exp Med 7: 5394-5402, 2014.

24. Mahlamäki EH, Bärlund M, Tanner M, Gorunova L, Höglund M, Karhu R and Kallioniemi A: Frequent amplification of 8q24, $11 \mathrm{q}, 17 \mathrm{q}$ and $20 \mathrm{q}$-specific genes in pancreatic cancer. Genes Chromosomes Cancer 35: 353-358, 2002.

25. Davis E, Teng H, Bilican B, Parker MI, Liu B, Carriera S, Goding CR and Prince S: Ectopic Tbx2 expression results in polyploidy and cisplatin resistance. Oncogene 27: 976-984, 2008.

26. Ismail A and Bateman A: Expression of TBX2 promotes anchorage-independent growth and survival in the p53-negative SW13 adrenocortical carcinoma. Cancer Lett 278: 230-240, 2009.

27. Wansleben S, Davis E, Peres J and Prince S: A novel role for the anti-senescence factor TBX2 in DNA repair and cisplatin resistance. Cell Death Dis 4: e846, 2013.

28. Tsuji K, Yamada R, Kawabata M, Mitsuzane K, Sato M, Iwahashi M, Kitayama S and Nakano R: Effect of balloon occluded arterial infusion of anticancer drugs on the prognosis of cervical cancer treated with radiation therapy. Int J Radiat Oncol Biol Phys 32: 1337-1345, 1995.

29. Sinicrope FA, Ruan SB, Cleary KR, Stephens LC, Lee JJ and Levin B: Bcl-2 and p53 oncoprotein expression during colorectal tumorigenesis. Cancer Res 55: 237-241, 1995.

30. Livak KJ and Schmittgen TD: Analysis of relative gene expression data using real-time quantitative PCR and the 2(-Delta Delta C(T)) method. Methods 25: 402-408, 2001

31. Kanda Y: Investigation of the freely available easy-to-use software 'EZR' for medical statistics. Bone Marrow Transplant 48: 452-458, 2013

32. Chen B, Wang L, Ren C, Shen H, Ding W, Zhu D, Mao L and Wang H: The effect of neoadjuvant chemotherapy on lymph node metastasis of FIGO stage IB1-IIB cervical cancer: A systematic review and meta-analysis. Front Oncol 10: 570258, 2020

33. de Vincenzo R, Ricci C, Fanfani F, Gui B, Gallotta V, Fagotti A, Ferrandina G and Scambia G: Neoadjuvant chemotherapy followed by conization in stage IB2-IIA1 cervical cancer larger than $2 \mathrm{~cm}$ : A pilot study. Fertil Steril 115: 148-156, 2021.

34. Sun Z, Huang B, Liu C, Yang Y, Rao Y, Du Y and Ma Y: Comparison of neoadjuvant treatments followed by radical surgery or chemoradiation on quality of life in patients with stage IB2-IIA cervical cancer. Gynecol Oncol 157: 536-541, 2020.

35. Panici PB, Bellati F, Manci N, Pernice M, Plotti F, Di Donato V, Calcagno M, Zullo MA, Muzii L and Angioli R: Neoadjuvant chemotherapy followed by radical surgery in patients affected by FIGO stage IVA cervical cancer. Ann Surg Oncol 14: 2643-2648, 2007.

36. Bose RN: Biomolecular targets for platinum antitumor drugs. Mini Rev Med Chem 2: 103-111, 2002.

37. Wang D and Lippard SJ: Cellular processing of platinum anticancer drugs. Nat Rev Drug Discov 4: 307-320, 2005.
38. Brabec V and Kasparkova J: Molecular aspects of resistance to antitumor platinum drugs. Drug Resist Updat 5: 147-161, 2002.

39. Galluzzi L, Senovilla L, Vitale I, Michels J, Martins I, Kepp O, Castedo M and Kroemer G: Molecular mechanisms of cisplatin resistance. Oncogene 31: 1869-1883, 2012.

40. Morimoto A, Serada S, Enomoto T, Kim A, Matsuzaki S, Takahashi T, Ueda Y, Yoshino K, Fujita M, Fujimoto M, et al: Annexin A4 induces platinum resistance in a chloride-and calcium-dependent manner. Oncotarget 5: 7776-7787, 2014.

41. Surowiak P, Materna V, Kaplenko I, Spaczyński M, Dietel M, Lage $\mathrm{H}$ and Zabel M: Augmented expression of metallothionein and glutathione S-transferase pi as unfavourable prognostic factors in cisplatin-treated ovarian cancer patients. Virchows Arch 447: 626-633, 2005.

42. Martin LP, Hamilton TC and Schilder RJ: Platinum resistance: The role of DNA repair pathways. Clin Cancer Res 14: 1291-1295, 2008.

43. Liu RY, Dong Z, Liu J, Yin JY, Zhou L, Wu X, Yang Y, Mo W, Huang W, Khoo SK, et al: Role of eIF3a in regulating cisplatin sensitivity and in translational control of nucleotide excision repair of nasopharyngeal carcinoma. Oncogene 30: 4814-4823, 2011.

44. Wang Q, Shi S, He W, Padilla MT, Zhang L, Wang X, Zhang B and Lin Y: Retaining MKP1 expression and attenuating JNK-mediated apoptosis by RIP1 for cisplatin resistance through miR-940 inhibition. Oncotarget 5: 1304-1314, 2014.

45. Liu RY, Dong Z, Liu J, Zhou L, Huang W, Khoo SK, Zhang Z, Petillo D, Teh BT, Qian CN and Zhang JT: Overexpression of asparagine synthetase and matrix metalloproteinase 19 confers cisplatin sensitivity in nasopharyngeal carcinoma cells. Mol Cancer Ther 12: 2157-2166, 2013.

46. Shen DW, Pouliot LM, Hall MD and Gottesman MM: Cisplatin resistance: A cellular self-defense mechanism resulting from multiple epigenetic and genetic changes. Pharmacol Rev 64: 706-721, 2012.

47. Fujiwara K, Daido S, Yamamoto A, Kobayashi R, Yokoyama T, Aoki H, Iwado E, Shinojima N, Kondo Y and Kondo S: Pivotal role of the cyclin-dependent kinase inhibitor p21WAF1/CIP1 in apoptosis and autophagy. J Biol Chem 283: 388-397, 2008.

48. Chen Z, Place RF, Jia ZJ, Pookot D, Dahiya R and Li LC: Antitumor effect of dsRNA-induced p21(WAF1/CIP1) gene activation in human bladder cancer cells. Mol Cancer Ther 7: 698-703, 2008

49. Wu ZM, Dai C, Huang Y, Zheng CF, Dong QZ, Wang G, Li XW, Zhang XF, Li B and Chen G: Anti-cancer effects of p21WAF1/CIP1 transcriptional activation induced by dsRNAs in human hepatocellular carcinoma cell lines. Acta Pharmacol Sin 32: 939-946, 2011.

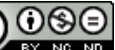

This work is licensed under a Creative Commons Attribution-NonCommercial-NoDerivatives 4.0 International (CC BY-NC-ND 4.0) License. 